\title{
Detection of reduced carbon in a basalt analogue for martian nakhlite: a signpost to habitat on Mars
}

\author{
John Parnell', Sean McMahon', Nigel J.F. Blamey², lan B. Hutchinson ${ }^{3}$, Liam V. Harris ${ }^{3}$, \\ Richard Ingley ${ }^{3}$, Howell G.M. Edwards ${ }^{3}$, Edward Lynch ${ }^{4}$ and Martin Feely ${ }^{4}$ \\ ${ }^{1}$ School of Geosciences, University of Aberdeen, Aberdeen AB24 3UE, UK \\ e-mail: j.parnell@abdn.ac.uk \\ ${ }^{2}$ Department of Earth and Environmental Sciences, New Mexico Tech, Socorro NM87801, USA \\ ${ }^{3}$ Department of Physics and Astronomy, University of Leicester, UK \\ ${ }^{4}$ Earth and Ocean Sciences, National University of Ireland, Galway, Republic of Ireland
}

\begin{abstract}
The Nakhla meteorite represents basaltic rock from the martian upper crust, with reduced carbon indicative of the ingress of carbonaceous fluids. Study of a terrestrial analogue basalt with reduced carbon from the Ordovician of Northern Ireland shows that remote analysis could detect the carbon using Raman spectroscopy. Analysis of gases released by crushing detects methane-rich fluids in the basalt and especially in cross-cutting carbon-bearing veinlets. The results suggest that automated analysis on Mars could detect the reduced carbon, which may be derived from magmatic and/or meteoritic infall sources.
\end{abstract}

Received 18 June 2013, accepted 11 September 2013, first published online 25 October 2013

Key words: basalt, carbon, Mars, nakhlite, Raman spectroscopy.

\section{Introduction}

In the search for evidence of the environmental history of the martian surface, and the possibility of life at some stage in the planet's history, a key component is reduced carbon, which may be evidence of former life or represent feedstock for potential life. Carbon is available to the surface environment through meteoritic infall (Sephton et al. 2002) and erosion of volcanic rocks that contain magmatic carbon (Steele et al. 2012; Agee et al. 2013), in addition to the possibility of biogenic carbonaceous matter. The martian surface could thus contain multiple populations of reduced carbon. However, reduced carbon has not yet been detected by a range of missions to Mars. Carbonate minerals, containing carbon in inorganic oxidized form, have been recorded (Michalski \& Niles 2010), which together with carbon dioxide $\left(\mathrm{CO}_{2}\right)$ in the martian atmosphere and magmatic carbon in martian meteorites provide evidence for a carbon cycle on Mars (Grady \& Wright 2006; Chassefiere \& Leblanc 2011). The mobility of carbon on Mars is also evident in fracture-bound carbon in the Nakhla meteorite, derived from martian basalt (Gibson et al. 2006; McKay et al. 2011). Basalts are widespread on Mars, so are readily accessible for sampling and analysis. The mixing of carbonaceous matter with basaltic bedrock on the asteroid Vesta (McCord et al. 2012) further emphasizes the potential of basalt to yield samples containing carbon for analysis.

Basalt-hosted carbon could have a relationship to life in both a consequential or causative manner. Basalt could incorporate carbon from organic matter disseminated in sediments through which the basaltic magma passed. It is even possible that basalt could concentrate carbon scavenged from sediments into carbon-rich structures. Alternatively, basalt could act as a feedstock of carbon to provide biomass for colonizing microbes. In this way, the discovery of carbon in (martian) basalt could be regarded as a signpost to habitat, i.e. the identification of carbon is a key aspect of the strategy for targeting where evidence of life should be sought.

The ExoMars mission, currently intended to fly in 2018, includes a Raman spectroscopy instrument (Edwards et al. 2012), whose targets for detection include reduced carbon. We report here the study of an analogue for the carbon-bearing Nakhla meteorite, representing near-surface martian crust, using Raman spectroscopy and other techniques to demonstrate the potential to detect the reduced carbon there. The analogue is a terrestrial basalt containing traces of reduced carbon in cross-cutting fractures.

\section{Geological setting}

The analogue sample site is at Helen's Bay, County Down, Northern Ireland (Irish Grid Reference J459831). Samples were taken from a coastal exposure of Upper Ordovician (Caradoc) basaltic pillow lava, described by Sharpe (1970) and Craig (1984). The lava is within a deep marine succession that includes black (organic carbon-rich) shales and sandstones, formed on the floor of the Iapetus Ocean (Craig 1984). The pillow lava is cross-cut by millimetre-scale veinlets of quartz with fragments of carbon (Fig. 1). The margins of the veinlets are red due to haematite precipitation, reflecting regional oxidative alteration during the Permo-Triassic 


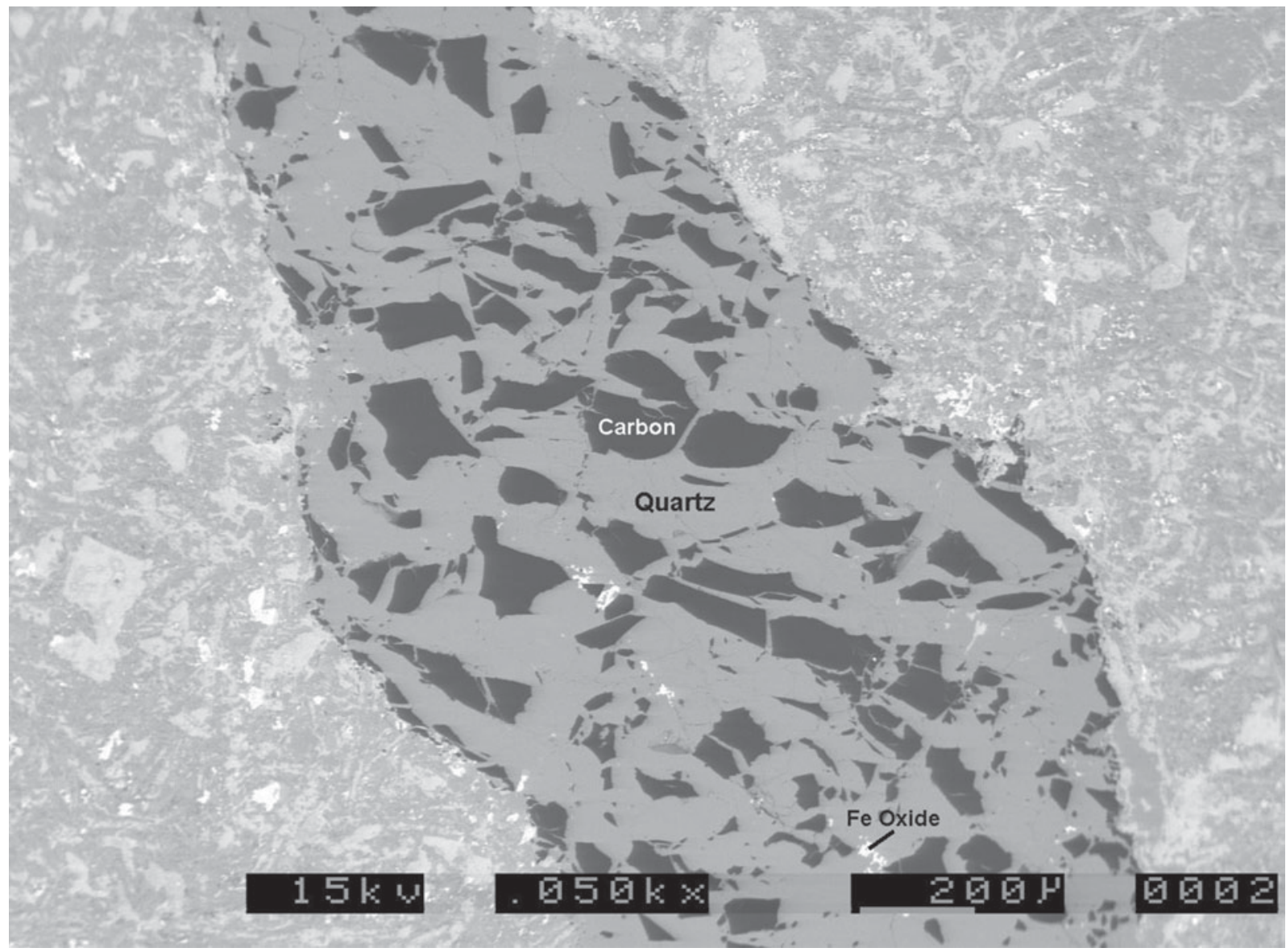

Fig. 1. Backscattered electron micrograph of quartz veinlet through Helens Bay basalt, showing numerous masses of carbon. Iron oxide (haematite) is also present in the veinlet and host basalt. Field width $2.2 \mathrm{~mm}$.

(Anderson et al. 1995). A control sample of basalt, of similar age and mineralogy (see below) but with no visible carbon, was sampled from Dounan's Point, southwest Scotland.

The Nakhla meteorite, representative of the nakhlites, is a cumulate igneous rock, containing augite and olivine crystals formed from a basaltic parental magma (Treiman 1993, 2003). It is cross-cut by a range of alteration phases, including phyllosilicates, carbonates, sulphates and halite (Needham et al. 2013). The terrestrial basalts were erupted in water at the planetary surface, hence they have a different genesis, but their mineralogy is broadly similar, and their hosting of crosscutting veinlets with carbonaceous matter makes them a suitable analogue for study of the carbon.

\section{Methodology}

\section{Petrography}

The basalt mineralogy was examined using an ISI ABT-55 scanning electron microscope with Link Analytical 10/55S EDAX facility. The organic carbon content of the basalt was measured using a LECO CS225 elemental analyser, with a detection limit of about $0.01 \mathrm{wt}$. \%. Three samples were measured from the analogue site at Helen's Bay, and one from the control site at Dounan's Point. Measurements were made on crushed samples of about $100 \mathrm{~g}$ mass, to ensure that they were representative.

\section{Raman spectroscopy of powdered samples}

Raman spectra were obtained using a portable Raman spectrometer which is similar in design to the Raman Laser Spectrometer (RLS) that is planned for launch on the ExoMars rover in 2018. The flight-like spectrometer incorporates a frequency doubled Nd:YAG laser with an excitation wavelength of $532 \mathrm{~nm}$ and a thermoelectrically cooled, chargecoupled device $(\mathrm{CCD})$ detector that provides a spectral range between 200 and $3400 \mathrm{~cm}^{-1}$ (and a maximum spectral resolution of $\left.10 \mathrm{~cm}^{-1}\right)$. The maximum output power of the laser was $\sim 100 \mathrm{~mW}$ and the laser footprint size was $\sim 200 \mu \mathrm{m}$ in diameter.

Three sites of interest were visually identified on the natural (unprepared) surface of the Helen's Bay sample rock; the carbon-carrying quartz veinlets and two surfaces selected to be representative of the bulk rock (one grey in colour and the other black). Twenty spectra were acquired from each of the three different surface regions, by random sampling. Integration times of between 20 and $60 \mathrm{~s}$ were used for each measurement, ensuring that near maximum dynamic range was achieved for each acquisition. The Raman shift and full-width 
at half-maximum (FWHM) of the carbon $G$ band was determined for each spectrum after subtracting a linear fit to the background from a narrow window around the band's expected position at $1580-1600 \mathrm{~cm}^{-1}$ (Ferrari \& Robertson 2000). The basalt from Dounan's Point, Scotland, was also analysed as a control.

The same measurement procedure was repeated after crushing a segment of the rock, so that the sample material would be representative of that expected to be obtained by the Exomars drill and Sample Preparation and Distribution System (SPDS) (Schulte et al. 2008). Measurements were made on a $250-297 \mu \mathrm{m}$ grain size fraction, within the particle size range to be provided by the SPDS.

\section{Raman spectroscopy of fluid inclusions}

Raman spectroscopy of fluid inclusions was conducted at the School of Natural Sciences, National University of Ireland Galway, using a Horiba LabRam II Raman spectrometer. The instrument is equipped with a 600 groove $\mathrm{mm}^{-1}$ diffraction grating, a confocal optical system, a Peltier-cooled CCD detector $\left(255\right.$ by 1024 pixel array at $-67^{\circ} \mathrm{C}$ ) and an Olympus BX41 microscope arranged in $180^{\circ}$ backscatter geometry. Sample excitation was performed using a Ventus diodepumped, continuous wavelength, $532 \mathrm{~nm}$ laser with a maximum power output of $50 \mathrm{~mW}$. The laser was channelled through a Leica L $100 \times / 0.75$ microscope objective, providing a laser spot diameter of $\sim 2 \mu \mathrm{m}$ and excitation power at the sample of $\sim 10-20 \mathrm{~mW}$. Individual analyses were performed in air at room temperature between 3 and $20 \mathrm{~s}$ over the spectral range $100-4000 \mathrm{~cm}^{-1}$. The number of spectral accumulations per analysis typically varied between 5 and 10 to maximize the signal-to-noise efficiency of the spectrometer. Instrument operating parameters, spectral acquisition settings and spectra manipulation were controlled using LabSpec v.5.78.24 (Horiba Scientific). Calibration of the LabRam instrument was performed before each analytical session and routinely between individual analyses using the Raman peak of an unstrained crystalline silicon wafer $\left(520.2 \pm 0.5 \mathrm{~cm}^{-1}\right.$; Parker et al. 1967). Uncertainty associated with the generation of Raman peak positions based on replicate analysis of the silicon standard is $\pm 1.0 \mathrm{~cm}^{-1}(2 \sigma ; 0.2 \%)$. Raman spectroscopy was also used to identify minerals in thin and thick sections of basalt (sensu Hope et al. 2001). The acquired mineral spectra were compared and identified using in-house (NUI Galway), commercial (Spectral ID v.3.0.3; Thermo Electron Corp.) and open source Raman spectral databases (e.g. RRUFF Project, Downs 2006; Siena Geofluids Laboratory, Frezzotti et al. 2012).

\section{Entrapped volatiles}

Entrapped gases were measured by the crush-fast scan (CFS) method (Parry \& Blamey 2010; Blamey 2012). Samples were analysed by incremental cold-CFS, or a bulk decrepitation/ crush method under an ultrahigh vacuum $\left(\sim 10^{-8}\right.$ Torr $)$ using Pfeiffer Prisma quadrupole mass spectrometers operating in fast-scan, peak-hopping mode. Two to ten bursts of fluid
Table 1. Gas compositions for samples of Helen's Bay basalt (methane, carbon dioxide, hydrogen, nitrogen, summed to $100 \%)$ and magnitude of gas released

\begin{tabular}{llrrrl}
\hline Sample & $\% \mathrm{CH}_{4}$ & $\% \mathrm{CO}_{2}$ & $\% \mathrm{H}_{2}$ & $\% \mathrm{~N}_{2}$ & $\begin{array}{l}\text { Total burst } \\
\text { (moles) }\end{array}$ \\
\hline Basalt 1 & 48.31 & 11.67 & 1.47 & 36.11 & $2.35 \times 10^{-10}$ \\
Basalt 2 & 26.88 & 2.03 & 52.76 & 10.33 & $3.06 \times 10^{-11}$ \\
Basalt 3 & 42.00 & 0.94 & 26.56 & 19.45 & $6.55 \times 10^{-11}$ \\
Vein & 85.18 & 8.51 & 0.01 & 6.21 & $3.13 \times 10^{-9}$ \\
Oxidation halo 1 & 48.07 & 5.01 & 10.67 & 28.36 & $4.61 \times 10^{-11}$ \\
Oxidation halo 2 & 63.73 & 8.13 & 6.54 & 16.55 & $1.21 \times 10^{-10}$ \\
\hline
\end{tabular}

(up to $\sim 2.0 \times 10^{-11} 1$ ) were released per sample and analysed for $\mathrm{H}_{2}, \mathrm{CH}_{4}, \mathrm{~N}_{2}$ and $\mathrm{CO}_{2}$, among other gases not pertinent to this study. Calibration was checked against commercial standard gas mixtures, atmospheric capillary tubes and three fluid-inclusion standards as described by Norman \& Blamey (2001). Instrumental blanks were also analysed routinely. The amount of each species was calculated by proprietary software to provide a quantitative analysis (Table 1), although crushing does not liberate all the entrapped gas from the samples. Data for entrapped gas are reported as methane $\left(\mathrm{CH}_{4}\right) /$ $\mathrm{CO}_{2}$ ratios, as a measure of whether the volatile carbonaceous component is dominated by oxidized or reduced carbon. Carbon dioxide is typically important in magmatic systems (Lowenstern 2001), but the incorporation of reduced carbon may give $\mathrm{CH}_{4} / \mathrm{CO}_{2}$ ratios above unity (McMahon et al. 2013). Gas ratios were measured in whole rock, chips of cross-cutting quartz/calcite veins and in a small sample of basalt conspicuously rich in carbon (i.e. with dark colour, more carbonaceous than the samples measured for organic carbon content).

\section{Results}

\section{Petrography}

The Helen's Bay basalt has an aphanitic texture and is pervasively altered, so that the primary silicate minerals (submillimetre-scale crystals of feldspars, pyroxene and olivine) are largely replaced by clay minerals and chlorite. It is cross-cut by millimetre-width veining of quartz and calcite, in which carbon occurs as angular fragments up to $200 \mu \mathrm{m}$ size (Fig. 1). There is also carbon in the altered groundmass, occurring as micronscale blebs. Another phase of veining is characterized by red iron oxide (haematite) staining forming oxidation halos around new hairline fractures and also around some of the earlier quartz/calcite veinlets (Fig. 1). The basalt exhibits pillowed surfaces at outcrop, but no glassy margins survive. Interstices between the pillows may contain small pockets of grey (i.e. carbon-bearing) sediment. The Donuan's Point control basalt has a similar mineralogy, but is also vesicular, with amygdales of calcite, chlorite and traces of pyrite. The mean of three measurements of the organic carbon content of the Helen's Bay basalt is 0.17 wt. \% (all samples $0.15-0.20$ wt. \%). A single sample of non-carbonaceous 


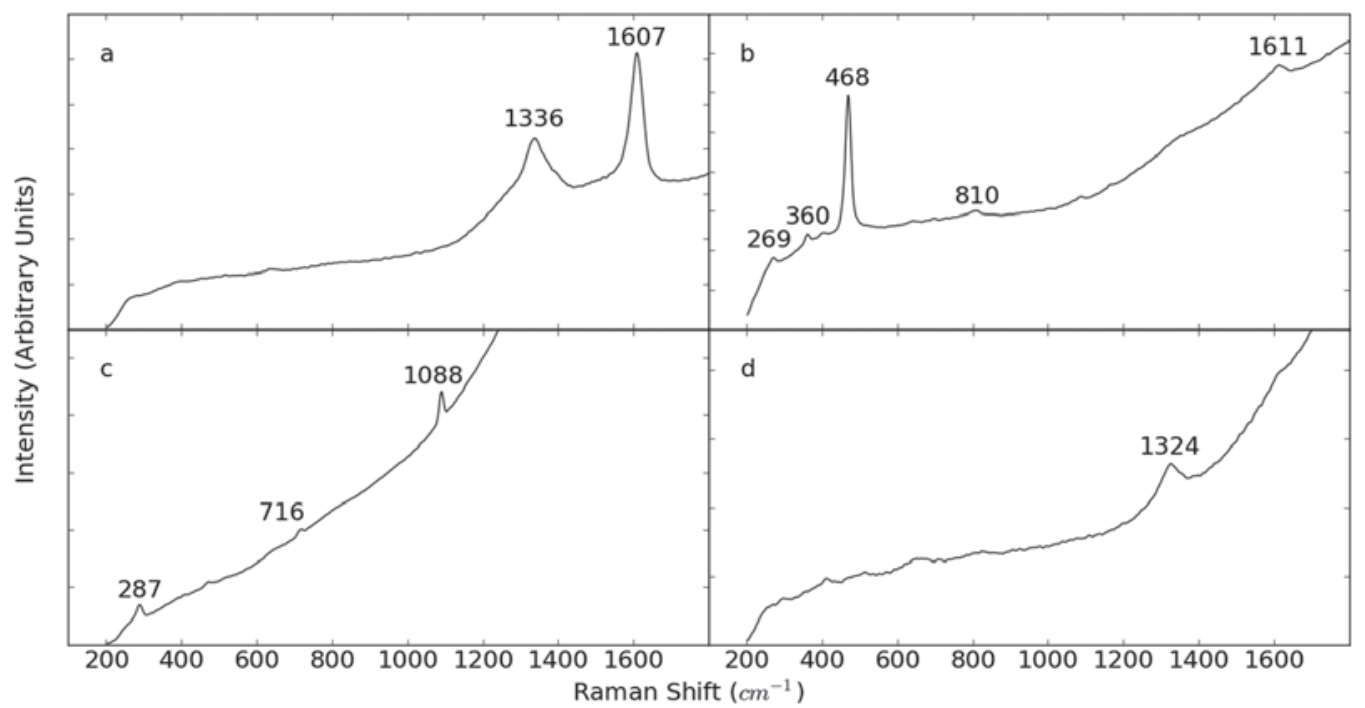

Fig. 2. Typical Raman spectra from the Helen's Bay sample. (a) Carbon. (b) The strong band at $468 \mathrm{~cm}^{-1}$ and the weaker ones at 269,360 and $810 \mathrm{~cm}^{-1}$ suggest the presence of quartz, while the band at $1611 \mathrm{~cm}^{-1}$ is the carbon G-band. (c) Calcite. (d) Haematite.

basalt from Dounan's Point contains 0.05 wt. \% organic carbon.

\section{Raman spectroscopy of powdered samples}

Several minerals have been identified in the Helen's Bay basalt using the bands that appear in the Raman spectra. Most significantly, the presence of reduced carbon is indicated by the carbon D- and G-bands, which appear at Raman shifts of around 1350 and $1580-1600 \mathrm{~cm}^{-1}$ (Ferrari \& Robertson 2000), visible in Fig. 2(a) at 1336 and $1607 \mathrm{~cm}^{-1}$. Also shown in Fig. 2 are spectra that demonstrate the detection of calcite, haematite and quartz. Quartz is identified by a strong band at $468 \mathrm{~cm}^{-1}$, as well as weaker bands at 269,360 and $810 \mathrm{~cm}^{-1}$ and calcite by bands at 287,716 and $1088 \mathrm{~cm}^{-1}$ (Jorge Villar \& Edwards 2006), the first two of which unambiguously differentiate it from the other polymorphs of calcium carbonate. Haematite is a relatively weak Raman scatterer and most of the bands in its spectrum were not visible above the background fluorescence and scatter. However, it was identifiable in some spectra by the band at $1324 \mathrm{~cm}^{-1}$ (de Faria et al. 1997), seen in Fig. 2(d).

Not only it is possible to determine whether there is reduced carbon present within a sample using Raman spectroscopy, but by measuring the position and width of the carbon G-band in terms of its Raman shift and FWHM it is also possible to differentiate between separate populations of carbon with different levels of ordering and thermal maturities (Figs. 3 and 4). These measurements were achieved by subtracting a linear fit to the background from a narrow window around the band's expected position before measuring its width and centroid, which is given as each band's position. The measurements from a number of spectra are represented by a cross-plot of G-band width and position (Fig. 4) which clearly shows two separate carbon populations, one found in the quartz veinlet and the other distributed homogeneously throughout the rock.

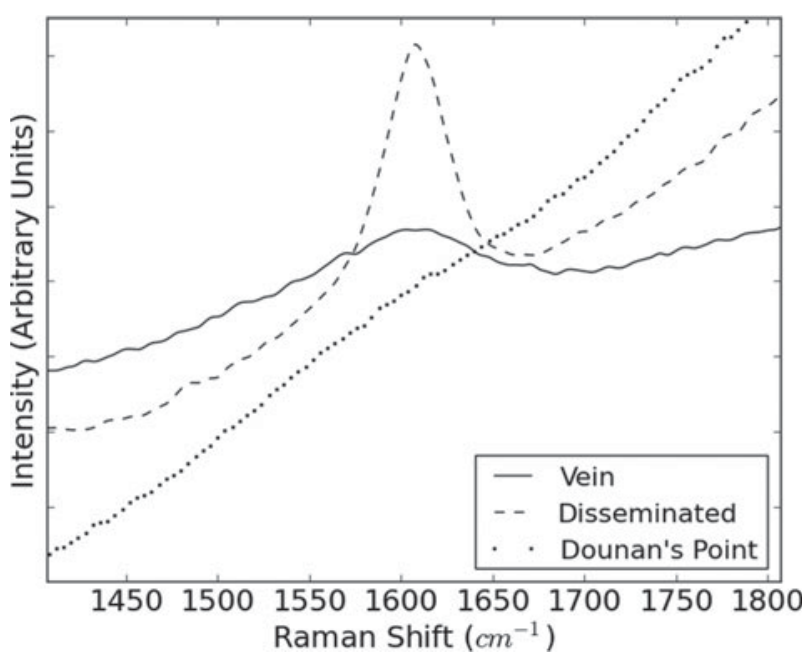

Fig. 3. Close-up view of the carbon G-band in three different spectra. The solid and dashed lines represent the two carbon populations in the Helen's Bay sample, found respectively in the quartz veinlet and homogeneously distributed throughout the rock. The dotted line is typical of the spectra from a sample from Dounan's Point; a basalt similar to that from Helen's Bay but without the reduced carbon signal.

The control sample of basalt from Dounan's Point showed no evidence of carbon (Fig. 3).

\section{Raman spectroscopy of fluid inclusions}

The quartz contains sparse monophase fluid inclusions. Raman spectroscopy of the entrained fluids indicates that some are aqueous, while others are dominated by $\mathrm{CH}_{4}$. The aqueous inclusions are two-phase (liquid and vapour), indicating temperatures of at least $60^{\circ} \mathrm{C}$ (Roedder 1984), but were not investigated further. The $\mathrm{CH}_{4}$ was identified by Raman shift peaks in the vicinity of $2917-2925 \mathrm{~cm}^{-1}$ (Fig. 5). 


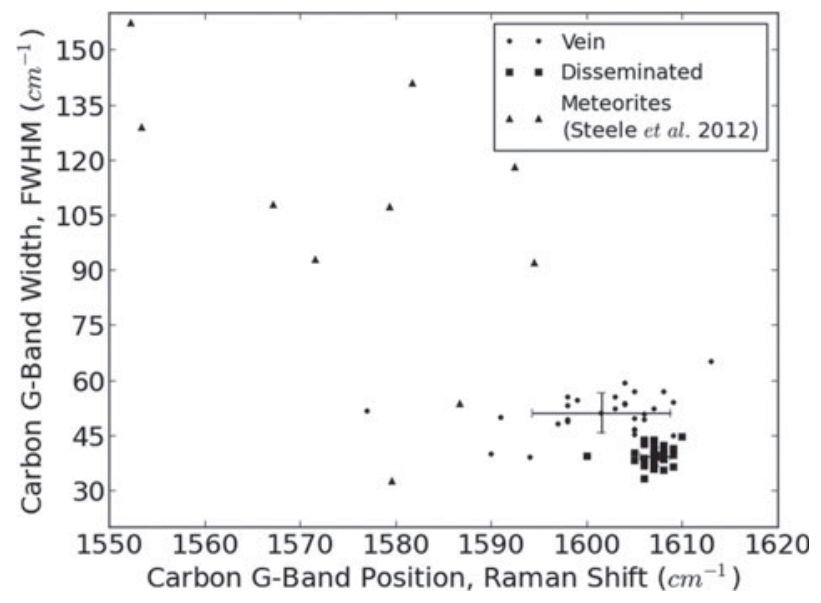

Fig. 4. Cross-plot of the position and width of the carbon G-band in Helen's Bay spectra, showing a clear separation between the two populations of carbon, one found in the quartz veinlet and the other homogeneously disseminated throughout the rock. The points with error bars represent the mean position and width of each population (note that the error bar for disseminated carbon is very small and obscured by the data symbol). Points marked by triangles are representative of data from the Martian meteorites measured by Steele et al. (2012) for comparison.

\section{Entrapped volatiles}

The cold-crush volatile data for entrapped gases from both solid basalt and cross-cutting veins yield relatively high $\mathrm{CH}_{4} / \mathrm{CO}_{2}$ ratios (Table 1, Fig. 6). The ratios are all above unity, in the range 4-14. The samples of veins, whether reddened or not, yield ratios comparable with the whole rock. The sample conspicuously rich in carbon gave a higher ratio of about 37. By contrast, modern fluids venting through volcanic rocks (Charlou et al. 2002; Stefánsson \& Arnórsson 2002) have much lower values (Fig. 6), and magmatic systems in general are rich in $\mathrm{CO}_{2}$ (Lowenstern 2001).

\section{Discussion}

\section{Detection of carbon and haematite by Raman}

The reduced carbon in the basalts was readily detected, in both particles and unprepared rock surfaces. The distinction of two populations of carbon is a significant result, as it gives rise to the possibility of differentiating between different sources of carbon within the same sample. This could be valuable on Mars, where reduced carbon may originate from magmatic sources, multiple generations of meteoritic infall and conceivably from martian life. The detection of haematite is also of interest, as it occurs on Mars and could have played a role in the evolution of primitive life (Christensen et al. 2001; Arora et al. 2007), whereby iron oxide precursors acted as a template for molecular evolution. In this study, the haematite peak was sufficiently separated from one of the carbon peaks at about $1335 \mathrm{~cm}^{-1}$ that they could be distinguished, but in a haematite-rich sample some overlap might occur, and the identification of carbon would rely on other peaks.

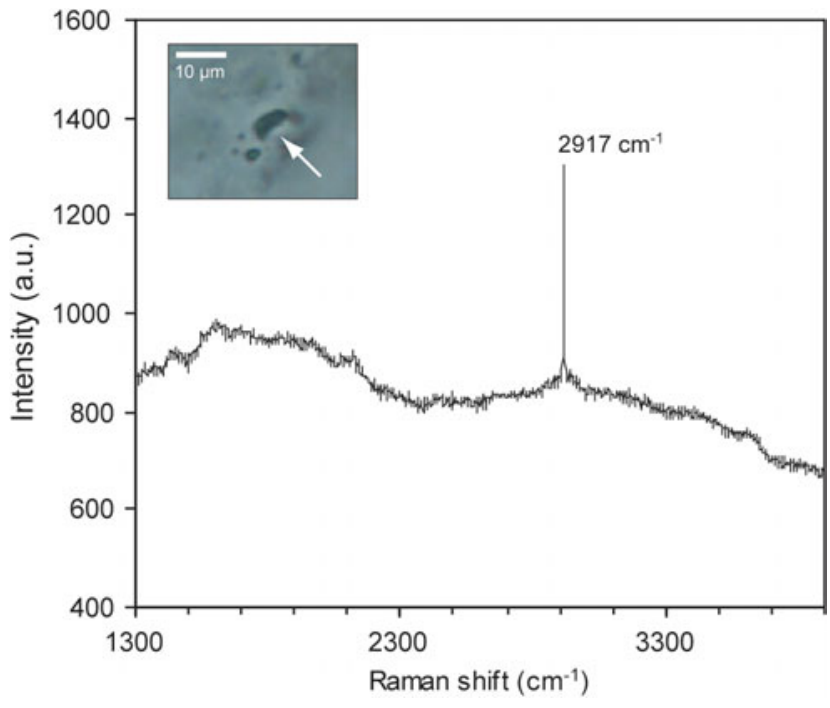

Fig. 5. Raman spectrum of monophase fluid inclusion in quartz, showing the prominent peak at $2917 \mathrm{~cm}^{-1}$, consistent with methane. The inset shows the micrograph of fluid inclusion used for measurement.

\section{Analogue with Nakhla}

The Helen's Bay basalt was chosen as an analogue because it is carbon-bearing. As in the Nakhla meteorite, carbon occurs in cross-cutting veinlets. The veinlets in Nakhla include linked blebs up to $10 \mu \mathrm{m}$ across, which are smaller than the larger fragments in Helens Bay basalt, but otherwise the occurrence of irregular blebs in a fracture-filling is comparable. Although the vein mineralogy is different from that of the iddingsite-rich veins in Nakhla (McKay et al. 2011), the migrated carbon in the Helen's Bay basalt makes it a suitable analogue for testing the detection of reduced carbon in the martian crust. However, the larger size of the carbonaceous fragments in the terrestrial basalt, which may reflect different vein mineralogy, does make their detection easier. The carbon in the groundmass of the Helens Bay basalt is also pertinent, as the traces of carbon recorded by Steele et al. (2012) in ten of 11 martian meteorites studied is within the bulk mineralogy. The carbon in the meteorites is preserved within high-temperature mineral grains and is attributed a magmatic origin. By contrast, the Helen's Bay basalt is within a succession that includes organic carbonbearing shales, so the most likely origin of the carbon in the basalt is from the thermal alteration of the shales by the basalt to generate hydrocarbons. This does not, however, negate the value of the analogue to test the detection of reduced carbon in basalt, although it would be valuable to undertake such a test on basalt containing magmatic carbon in the future. The Raman signatures of the veinlet carbon at Helens Bay can be compared (Fig. 4) with those obtained from martian meteorites (Steele et al. 2012). The lower wave number for the G-band in the meteorite carbon implies greater structural ordering of the carbon and higher thermal maturity (Wopenka \& Pasteris 1993), but for a proper comparison the samples need to be measured under identical conditions and using identical software for processing of the spectra. 


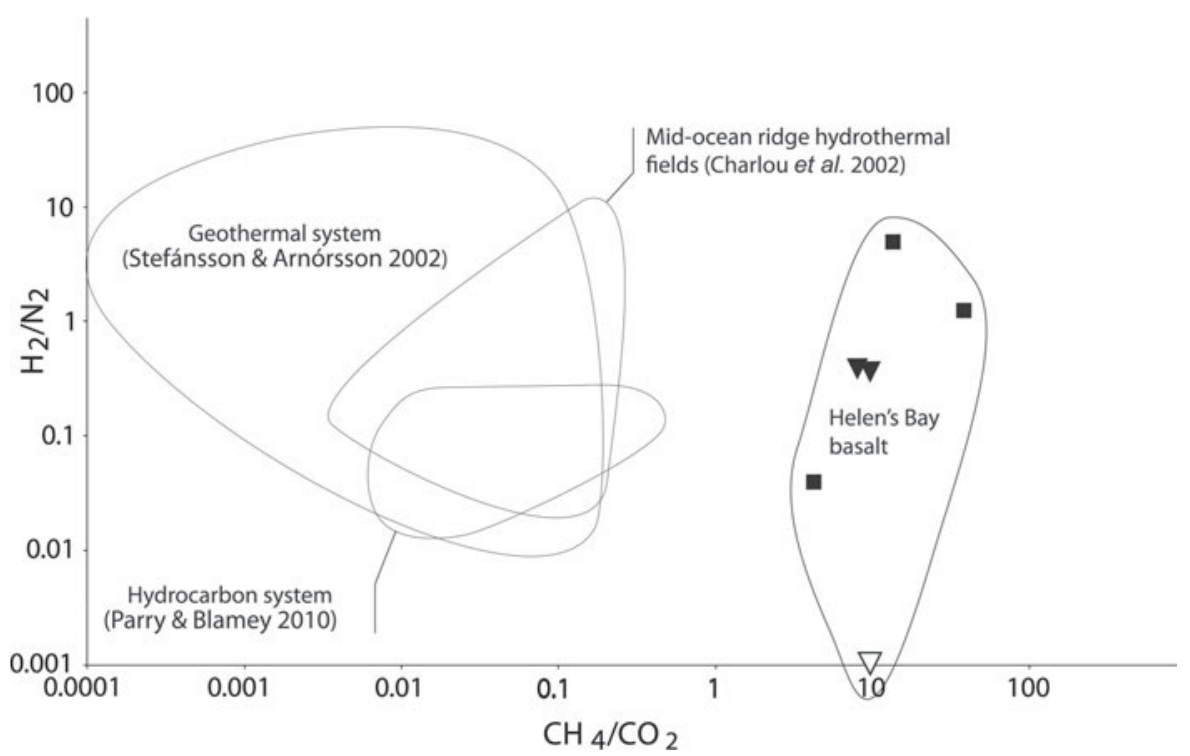

Fig. 6. Cross-plot of gas compositions $\left(\mathrm{CH}_{4} / \mathrm{CO}_{2}\right.$ against $\left.\mathrm{H}_{2} / \mathrm{N}_{2}\right)$ released by crushing of basalt samples from Helen's Bay, in comparison with three younger systems (Charlou et al. 2002; Stefánsson \& Arnórsson 2002; Parry \& Blamey 2010). Black squares represent solid basalt (sample with highest $\mathrm{CH}_{4} / \mathrm{CO}_{2}$ ratio is conspicuously rich in carbon); white triangle represents quartz vein through basalt; black triangle represents haematitic oxidation halo around the vein. Helen's Bay samples have distinctly greater $\mathrm{CH}_{4} / \mathrm{CO}_{2}$ ratios than in younger systems.

\section{Entrapped volatiles}

Although the entrained reduced carbon is an obvious source of $\mathrm{CH}_{4}$, the high $\mathrm{CH}_{4} / \mathrm{CO}_{2}$ ratios are also typical of data from basalts (McMahon et al. 2013). This may reflect the susceptibility of basalts to serpentinization, but also could represent the product of redox reactions in hydrothermal fluids (Lyons et al. 2005). The data from the Helen's Bay basalt are unlike that from modern fluids in volcanic rocks, and are more similar to published datasets from serpentinites and hydrothermal veins through organic-rich sediments (Parnell et al. 2010; McMahon et al. 2012), both dominated by $\mathrm{CH}_{4}$. In both serpentinites and basalts, hydrogen produced by the reaction of silicates with water in turn reacts with $\mathrm{CO}_{2}$ to yield $\mathrm{CH}_{4}$, and this is proposed to also occur on Mars (Sleep et al. 2004; Oze \& Sharma 2007). In the case of Helen's Bay, the associated sedimentary rocks are an additional potential source of $\mathrm{CH}_{4}$.

\section{Circulation of carbon-bearing fluids}

The observations of carbonaceous matter in the cross-cutting mineral veins show that reduced carbon was entrained within the hydrothermal system that post-dated basalt extrusion. This is also evident from the analytical techniques. Firstly, the high $\mathrm{CH}_{4} / \mathrm{CO}_{2}$ ratios determined in the cross-cutting veins indicate that reduced carbon was circulating in the hydrothermal system. Secondly, the spectroscopic determination of $\mathrm{CH}_{4}$ in fluid inclusions supports the chemical data. Thirdly, the Raman data for the solid particles shows a spatial association of carbon with quartz, implying that some carbon is entrained in a mineral segregation, which in the case of quartz in basalt is most likely to be superimposed later. This latter measurement is achievable using mission-ready technology, so is feasible on Mars.

\section{Potential to detect on Mars}

The measurement of reduced carbon, using a Raman spectroscopy instrument designed for use during the ExoMars mission in 2018, demonstrates the capability to detect such material during that and other future missions. Deployed alongside established techniques for performing geological and biological analyses in situ on other planetary bodies, Raman spectrometers will increase the science return of future planetary rovers enormously (Wang et al. 2003; Courrèges-Lacoste et al. 2007). The RLS instrument on the ExoMars rover will help determine the chemistry and geology of samples delivered to the science payload from up to $2 \mathrm{~m}$ below the martian surface. Future instruments will analyse the surface features without any sample preparation, either while offered up to outcrops and surface features on a robot arm or surveyed from a mast instrument at greater distances.

Previous studies of organic compounds, using Raman spectroscopy, intended to support the exploration of Mars have focused on biomolecules that might be found in extant life, such as pigments (Edwards 2007; Edwards et al. 2007). Given the focus of future missions on the possibility of life in the martian geological record, as opposed to extant life (e.g. Vago et al. 2006), the measurement of reduced carbon is more relevant.

The detection of $\mathrm{CH}_{4}$ by Raman analysis of fluid inclusions, and by analysis of the volatile fraction of crushed samples, offers supporting evidence of reduced carbon. The remote measurement of $\mathrm{CH}_{4}$ and other volatile components liberated from solid rock samples, without thermal alteration of the samples, will require significant technological advance, but progress in miniaturizing spectroscopic techniques (e.g. EvansNguyen et al. 2008; Brinckerhoff et al. 2011) offers hope that such measurements will become possible. 


\section{Conclusions}

The reduced carbon in the basalt was successfully detected in a format (a specific grain size fraction) that replicates the sample preparation system intended for the ExoMars mission.

Measurements relevant to the exploration of Mars include:

(i) Resolution of the Raman data for reduced carbon was high enough to distinguish more than one population of carbon.

(ii) The specific occurrence of carbon in a mineral (quartz) vein shows that carbonaceous matter was incorporated in a hydrothermal system. Combined with imaging to provide context, an occurrence of this type would be an important component of the carbon cycle on Mars.

(iii) The Raman data also recorded associated minerals, including the quartz host to veinlet carbon, and the haematite indicative of oxidation.

\section{Acknowledgements}

C. W. Taylor and J. Still are thanked for skilled technical support. J. Parnell, H.G.M. Edwards, I. Hutchinson and R. Ingley acknowledge the support of the UKSA and the STFC Research Council in the UK ExoMars programme. L. V. Harris and S. McMahon acknowledge STFC studentship funding. We are grateful to P. Lindgren for a thorough and helpful review.

\section{References}

Agee, C.B. et al. (2013). Unique meteorite from early Amazonian Mars: water-rich basaltic breccia Northwest Africa 7034. Science 339, 780-785.

Anderson, T.B., Parnell, J. \& Ruffell, A.H. (1995). Influence of basement on the geometry of Permo-Triassic basins in the Northwest British Isles. Geol. Soc. Spec. Publ. 91, 103-122.

Arora, A.K., Tomar, V., Aarti, N., Venkateswararao, K.T. \& Kamaluddin (2007). Haematite-water system on Mars and its possible role in chemical evolution. Int. J. Astrobiol. 6, 267-271.

Blamey, N.J.F. (2012). Composition and evolution of crustal fluids interpreted using quantitative fluid inclusion gas analysis. J. Geochem. Explor. 116-117, 17-27.

Brinckerhoff, W.B., Mahaffy, P.R. \& the MSL/SAM and ExoMars/MOMA Investigation Teams (2011). Mass spectrometry on future Mars landers. In Lunar and Planetary Institute, Conference on Analogue Sites for Mars Missions, abstract 6038.

Charlou, J., Donval, J., Fouquet, Y., Jean-Baptiste, P. \& Holm, N. (2002). Geochemistry of high $\mathrm{H}_{2}$ and $\mathrm{CH}_{4}$ vent fluids issuing from ultramafic rocks at the Rainbow hydrothermal field $\left(36^{\circ} 14^{\prime} \mathrm{N}, \mathrm{MAR}\right)$. Chem. Geol. 191, 345-359.

Chassefiere, E. \& Leblanc, F. (2011). Methane release and the carbon cycle on Mars. Planet. Space Sci. 59, 207-217.

Christensen, P.R., Morris, R.V., Lane, M.D., Bandfield, J.L. \& Malin, M.C. (2001). Global mapping of Martian hematite mineral deposits: remnants of water-driven processes on early Mars. J. Geophys. Res. 106, $23873-$ 23885 .

Courrèges-Lacoste, G., Ahlers, B. \& Rull, F. (2007). Combined Raman spectrometer/laser-induced breakdown spectrometer for the next ESA mission to Mars. Spectrochim. Acta A 68, 1023.

Craig, L.E. (1984). Stratigraphy in an accretionary prism: the Ordovician rocks in North Down, Ireland. Trans. R. Soc. Edinb., Earth Sci. 74, 183-191. de Faria, D.L.A., Venâncio Silva, S. \& de Oliveira, M.T. (1997). Raman microspectroscopy of some iron oxides and oxyhydroxides. J. Raman Spectrosc. 28, 873-878.

Downs, R.T. (2006). The RRUFF Project: an integrated study of the chemistry, crystallography, Raman and infrared spectroscopy of minerals. In Program and Abstracts of the 19th General Meeting of the Int. Mineralogical Association, Kobe, Japan. O03-13.

Edwards, H.G., Vandenabeele, P., Jorge-Villar, S.E., Carter, E.A., Perez, F.R. \& Hargreaves, M.D. (2007). The Rio Tinto Mars analogue site: an extremophilic Raman spectroscopic study. Spectrochim. Acta A 68, 1133-1137.

Edwards, H.G.M. (2007). Raman spectroscopic approach to analytical astrobiology: the detection of key biomolecular markers in the search for life. Orig. Life Evol. Biosph. 37, 335-339.

Edwards, H.G.M., Hutchinson, I. \& Ingley, R. (2012). The ExoMars Raman spectrometer and the identification of biogeological spectroscopic signatures using a flight-like prototype. Anal. Bioanal. Chem. 404, 17231731.

Evans-Nguyen, T., Becker, L., Doroshenko, V. \& Cotter, R.J. (2008). Development of a low power, high mass range spectrometer for Mars surface analysis. Int. J. Mass Spectrom. 278, 170-177.

Ferrari, A.C. \& Robertson, J. (2000). Interpretation of Raman spectra of disordered and amorphous carbon. Phys. Rev. B 61, 14095-14107.

Frezzotti, M.L., Tecce, F. \& Casagli, A. (2012). Raman spectroscopy for fluid inclusion analysis. J. Geochem. Explor. 112, 1-20.

Gibson, E.K. et al. (2006). Identification and analysis of carbon-bearing phases in the martian meteorite Nakhla. Proc. SPIE 6309, 630901. DOI: $10.1117 / 12.690503$.

Grady, M.M. \& Wright, I. (2006). The carbon cycle on early Earth - and on Mars? Phil. Trans. R. Soc. B 361, 1703-1713.

Hope, G.A., Woods, R. \& Munce, C.G. (2001). Raman microprobe mineral identification. Miner. Eng. 14, 1565-1577.

Jorge Villar, S.E. \& Edwards, H.G.M. (2006). Raman spectroscopy in astrobiology. Anal. Bioanal. Chem. 384, 100-113.

Lowenstern, J.B. (2001). Carbon dioxide in magmas and implications for hydrothermal systems. Mineral. Deposita 36, 490-502.

Lyons, J.R., Manning, C. \& Nimmo, F. (2005). Formation of methane on Mars by fluid-rock interaction in the crust. Geophys. Res. Lett. 32, L13201.

McCord, T.B. et al. (2012). Dark material on Vesta from the infall of carbonaceous volatile-rich material. Nature 491, 83-86.

McKay, D.S., Thomas-Keprta, K.L., Clemett, S.J., Gibson, E.K., Le, L., Rahman, Z. \& Wentworth, S.J. (2011). Organic carbon features identified in the Nakhla martian meteorite. In 42nd Lunar and Planetary Science Conf., abstract 2673.

McMahon, S., Parnell, J. \& Blamey, N.J.F. (2012). Sampling methane in hydrothermal minerals on Earth and Mars. Int. J. Astrobiol. 11, 163-167.

McMahon, S., Parnell, J. \& Blamey, N.J.F. (2013). Sampling methane in basalt on Earth and Mars. Int. J. Astrobiol. 12, 113-122.

Michalski, J.R. \& Niles, P.B. (2010). Deep crustal carbonate rocks exposed by meteor impact on Mars. Nat. Geosci. 3, 751-755.

Needham, A.W., Abel, R.L., Tomkinson, T. \& Grady, M.M. (2013). Martian subsurface fluid pathways and 3D mineralogy of the Nakhla meteorite. Geochim. Cosmochim. Acta 116, 96-110.

Norman, D.I. \& Blamey, N.J.F. (2001). Quantitative analysis of fluid inclusion volatiles by a two quadrupole mass spectrometer system. Eur. Curr. Res. Fluid Incl. XVI, 341-344.

Oze, C. \& Sharma, M. (2007). Serpentinization and the inorganic synthesis of $\mathrm{H}_{2}$ in planetary surfaces. Icarus $\mathbf{1 8 6}$, 557-561.

Parker, J.H. Jr., Feldman, D.W. \& Ashkin, M. (1967). Raman scattering by silicon and germanium. Phys. Rev. 155, 712-714.

Parnell, J., Boyce, A.J. \& Blamey, N.J.F. (2010). Follow the methane: the search for a deep biosphere, and the case for sampling serpentinites, on Mars. Int. J. Astrobiol. 9, 193-200.

Parry, W.T. \& Blamey, N.J.F. (2010). Fault fluid composition from fluid inclusion measurements, Laramide Age Uinta Thrust Fault, Utah. Chem. Geol. 278, 105-119.

Roedder, E. (1984). Fluid inclusions. Mineral. Soc. Am. Rev. Mineral. 12, 646 . 
Schulte, W., Widani, C., Hofmann, P., Bönke, T., Re, E. \& Baglioni, P. (2008). Design and breadboarding of the sample preparation and distribution system of the ExoMars mission. In Proc. Ninth Int. Symp. Artificial Intelligence, Robotics and Automation in Space.

Sephton, M.A., Wright, I.P., Gilmour, I., de Leeuw, J.W., Grady, M.M. \& Pillinger, C.T. (2002). High molecular weight organic matter in martian meteorites. Planet. Space Sci. 50, 711-716.

Sharpe, E.N. (1970). An occurrence of pillow lavas in the Ordovician of County Down. Irish Natural. J. 16, 299-301.

Sleep, N.H., Meibom, A., Fridriksson, T., Coleman, R.G. \& Bird, D.K (2004). $\mathrm{H}_{2}$-rich fluids from serpentinization: geochemical and biotic implications. Proc. Natl. Acad. Sci.USA 101, 12818-12823.

Steele, A. et al. (2012). A reduced organic carbon component in martian basalts. Science 337, 212-215.

Stefánsson, A. \& Arnórsson, S. (2002). Gas pressures and redox reactions in geothermal fluids in Iceland. Chem. Geol. 190, 251-271.
Treiman, A.H. (1993). The parental magma of the Nakhla (SNC) achondrite, inferred from magmatic inclusions. Geochim. Cosmochim. Acta 57, 47534767.

Treiman, A.H. (2003). The Nakhla martian meteorite is a cumulate igneous rock. Mineral. Petrol. 77, 271-277.

Vago, J., Gardini, B., Kminek, G., Baglioni, P., Gianfiglio, G., Santovincenzo, A., Bayon, S. \& van Winnendael, M. (2006). ExoMars: searching for life on the Red Planet. Eur. Space Agency Bull. 126, 17-23.

Wang, A., Haskin, L.A., Lane, A.L., Wdowiak, T.J., Squyres, S.W., Wilson, R.J., Hovland, L.E., Manatt, K.S., Raouf, N. \& Smith, C.D. (2003). Development of the Mars microbeam Raman spectrometer (MMRS). J. Geophys. Res. 108, 5005.

Wopenka, B. \& Pasteris, J.D. (1993). Structural characterization of kerogens to granulite-facies graphite: applicability of Raman microprobe spectroscopy. Am. Mineral. 78, 533-557. 